\title{
Digital Approaches to Automated and Machine Learning Assessments of Hearing: Scoping Review
}

Jan-Willem Wasmann ${ }^{1 *}$, MSc; Leontien Pragt ${ }^{1 *}$, MSc; Robert Eikelboom ${ }^{2,3,4}, \mathrm{PhD}$; De Wet Swanepoel ${ }^{2,3,4}, \mathrm{PhD}$

${ }^{1}$ Department of Otorhinolaryngology, Donders Institute for Brain, Cognition and Behaviour, Radboud University Medical Centre, Nijmegen, Netherlands

${ }^{2}$ Ear Science Institute Australia, Subiaco, Australia

${ }^{3}$ Ear Sciences Centre, Medical School, The University of Western Australia, Perth, Australia

${ }^{4}$ Department of Speech-Language Pathology and Audiology, University of Pretoria, Pretoria, South Africa

*these authors contributed equally

\section{Corresponding Author:}

Jan-Willem Wasmann, MSc

Department of Otorhinolaryngology, Donders Institute for Brain, Cognition and Behaviour

Radboud University Medical Centre

Philips van Leydenlaan 15

Nijmegen, $6500 \mathrm{HB}$

Netherlands

Phone: 31024361042

Email: Jan-Willem.Wasmann@ radboudumc.nl

\section{Abstract}

Background: Hearing loss affects 1 in 5 people worldwide and is estimated to affect 1 in 4 by 2050 . Treatment relies on the accurate diagnosis of hearing loss; however, this first step is out of reach for $>80 \%$ of those affected. Increasingly automated approaches are being developed for self-administered digital hearing assessments without the direct involvement of professionals.

Objective: This study aims to provide an overview of digital approaches in automated and machine learning assessments of hearing using pure-tone audiometry and to focus on the aspects related to accuracy, reliability, and time efficiency. This review is an extension of a 2013 systematic review.

Methods: A search across the electronic databases of PubMed, IEEE, and Web of Science was conducted to identify relevant reports from the peer-reviewed literature. Key information about each report's scope and details was collected to assess the commonalities among the approaches.

Results: A total of 56 reports from 2012 to June 2021 were included. From this selection, 27 unique automated approaches were identified. Machine learning approaches require fewer trials than conventional threshold-seeking approaches, and personal digital devices make assessments more affordable and accessible. Validity can be enhanced using digital technologies for quality surveillance, including noise monitoring and detecting inconclusive results.

Conclusions: In the past 10 years, an increasing number of automated approaches have reported similar accuracy, reliability, and time efficiency as manual hearing assessments. New developments, including machine learning approaches, offer features, versatility, and cost-effectiveness beyond manual audiometry. Used within identified limitations, automated assessments using digital devices can support task-shifting, self-care, telehealth, and clinical care pathways.

(J Med Internet Res 2022;24(2):e32581) doi: 10.2196/32581

\section{KEYWORDS}

audiology; automated audiometry; automatic audiometry; automation; digital health technologies; digital hearing health care; machine learning; remote care; self-administered audiometry; self-assessment audiometry; user-operated audiometry; digital health; hearing loss; digital hearing; digital devices; mobile phone; telehealth 


\section{Introduction}

\section{Background}

Hearing loss affects 1.5 billion persons worldwide and is expected to increase by another billion by 2050 [1,2]. Hearing testing is the first step toward appropriate and timely treatment. Unfortunately, most persons affected with hearing loss are unable to access hearing assessments, with less than one hearing health professional for every million people in regions such as Africa [2,3]. Increasingly automated approaches (all aspects of the method associated with automated audiometry), including machine learning, are being developed and made available to provide self-administered hearing assessments. The term automated audiometry refers to all hearing tests that are self-administered from the point the test starts. More specifically, in this review, we define automated audiometry as calibrated pure-tone threshold audiometry in any setting (ie, hearing health care, occupational health, and community settings) that is self-administered from the point the test starts. Machine learning refers to model-based approaches that learn from examples (data) instead of being programmed with rules [4]. As the direct involvement of professionals is not required, automated approaches enable health care pathways with the potential to increase accessibility, efficiency, and scalability. Digital (health) technologies, including apps, smartphones, tablets, and wearables, can acquire data remotely; expand the reach and precision of clinicians; and facilitate more personalized hearing health care within a network of distributed expertise [5,6]. Recent examples of automated hearing assessments include clinical grade and consumer-grade applications [7]. General global health trends suggest that increased availability of diagnostic tools could lower health care costs and improve quality of life [8]. For example, in Parkinson disease, remote care based on wearables provides ecologically valid methods for monitoring and evaluating symptoms $[9,10]$. In tuberculosis screening in low-resource settings, an automated diagnosis can increase the sensitivity of identifying persons at risk while reducing costs [11]. Self-assessment using eHealth vision tools improves access to diagnosis and facilitates timely diagnosis, although consistent criteria for referring to the clinical pathway and validity and reliability of eHealth tools are still a concern [12].

Timely detection and treatment of hearing loss are essential to enable optimal outcomes and quality of life across the life span [2]. Untreated hearing loss restricts language development and educational potential in children and is associated with a more rapid cognitive decline in adults [13]. It may lead to social isolation, lower socioeconomic status, increased social disparities, and decreased health, resulting in lower quality of life at the individual level and substantial costs at the community level $[14,15]$. Importantly, treating hearing loss in midlife has been identified as the largest potentially modifiable risk factor for developing dementia in later life [16]. The global annual cost of untreated hearing loss is US $\$ 980$ million [14]. Global health investment models indicate a significant return on investment in both hearing diagnosis and treatment [2]. The capacity of the entire clinical pathway should be increased as a bottleneck looms if the accessibility of diagnosis is increased faster than the availability of affordable treatment and rehabilitation.

Automated self-test options are important for detecting and diagnosing hearing loss to direct timely and appropriate treatments. The overwhelming majority of treatments are for permanent age-related and noise-induced hearing loss; however, a significant portion of the population requires medical treatment for hearing loss [1]. The onset of the COVID-19 pandemic has further emphasized the importance of self-testing approaches $[17,18]$. Automation on digital devices is a powerful enabler of alternative diagnostic pathways that can include home-based testing, low-touch service models outside traditional clinic settings, and decentralized community-based models that rely on task shifting to minimally trained facilitators [19].

Automation in hearing assessment is not a new concept and dates back to $>7$ decades [20]. In recent years, it has resurged with the convergence of digital technologies and machine learning approaches. The primary tool for hearing assessment is pure-tone audiometry, which describes the degree of hearing loss relative to normal hearing, expressed in decibels hearing level across specific frequencies $(125-8000 \mathrm{~Hz})$. Pure-tone audiometry can also differentiate the type of hearing loss, that is, sensorineural or conductive, when bone conduction and air conduction transducers are used. Machine learning-based threshold-seeking approaches, known as Bayesian active learning, have demonstrated their potential to optimize efficiency and increase the precision of automated hearing assessments [21]. The increased efficiency comes from the ability of these methods to target trials to those areas of the frequency space where the estimation has the greatest uncertainty $[22,23]$.

\section{Objective}

In 2013, a systematic review that included 29 reports on automated audiometry showed that automated procedures have comparable accuracy with that of manual procedures when performing air conduction audiometry. Although a few validated automated procedures that included automated bone conduction audiometry had been reported, machine learning-based audiometry approaches had not been reported yet, and approaches were rarely validated in children or hard-to-test populations [24]. Since 2013, there has been significant work and innovation in this area, which calls for an update and extension of the previous review. This study aims to provide the current status of automation and machine learning approaches in hearing assessment using validated pure-tone audiometry with potential indicators of accuracy, reliability, and efficiency of these approaches.

\section{Methods}

We conducted a systematic scoping review of the peer-reviewed literature on automated and machine learning approaches to validate pure-tone threshold audiometry using digital technologies by considering accuracy, reliability, and efficiency. This review followed the methodological framework outlined by Arksey and O’Malley [25]. 


\section{Identifying Potentially Relevant Records}

A search across the electronic databases of PubMed, IEEE, and Web of Science was conducted to identify relevant reports from the peer-reviewed literature. Complementary and redundant search terms were applied to ensure thorough coverage and cross-checking of the search findings. In the PubMed database, medical subject headings and relevant keywords were collected to determine all records related to the study aim. The following synonyms of, and closely related terms to, automated audiometry were used: automatic audiometry, self-administered audiometry, self-assessment audiometry, and user-operated audiometry. The complete set of terms and the applied search strategy are provided in Multimedia Appendix 1. The IEEE database is engineering oriented, and only relevant keywords based on audiometry were used, as it was assumed that any result in audiometry would be highly associated with automated audiometry. The Web of Science database is known to index the PubMed and IEEE databases and was explored using search terms similar to the PubMed search. After preliminary explorations to identify appropriate keywords, we conducted a search on July 8, 2020, and updated it on January 12, 2021, and July 6, 2021. The search included all reports that met the inclusion criteria published from January 1, 2012, to June 30 , 2021. The start date was chosen as we regard this scoping review as an extension and generalization of a previous (systematic) review by Mahomed et al [24], which included studies up to July 20, 2012.

\section{Selecting Relevant Records}

Reports had to meet the following three inclusion criteria: (1) the report had to be about automated or machine learning and pure-tone frequency-specific threshold audiometry, (2) it had to be written in English, and (3) the automated threshold audiometry had to be compared against the gold standard or reasonable standard. The gold standard is defined as manual audiometry in a sound booth according to the International Organization for Standardization standards. Automated audiometry also needed to be performed inside a sound booth, and the results needed to be compared with the gold standard. A reasonable standard for validation was defined as either a within-subject comparison between the gold standard and the automated audiometry in an unconventional setting (eg, a quiet room) or a within-subject comparison between a validated automated audiometry approach and an experimental approach of audiometry in the same unconventional setting.

We excluded reports on screening audiometry (eg, provided pass or refer as an outcome) rather than threshold audiometry, review papers, and studies reporting approaches that were not compared with the gold or reasonable reference standard.

The first phase of screening was based on the title. If the title indicated that content was within the scope of the research question (ie, automated or machine learning approaches in diagnostic hearing assessment), the report was included in the second screening phase. In the second phase, the abstracts of the remaining reports were assessed using the inclusion and exclusion criteria stated earlier.

Two researchers (LP and JWW) conducted the abstract screening. They were blinded from each other to avoid confirmation bias. After the screening, the researchers discussed any disagreements to reach an agreement. When in doubt, the report was admitted to the third, full-text review phase. In this phase, all the remaining reports were reviewed in full to determine whether the inclusion criteria were met. As can be seen in the PRISMA (Preferred Reporting Items for Systematic Reviews and Meta-Analyses) flow diagram (Figure 1), the resulting selection of reports was complemented by additional reports. After some reports were clustered as having identical approaches (explained in Collating Approaches, Summarizing, and Reporting the Results), additional reports were added to avoid missing validation data of these clustered approaches. These additional reports were published before the inclusion date criteria (from before January 1, 2012) or did not appear in the search and were added based on the reference lists of the already included reports. 
Figure 1. PRISMA (Preferred Reporting Items for Systematic Reviews and Meta-Analyses) flow diagram of the screening process.

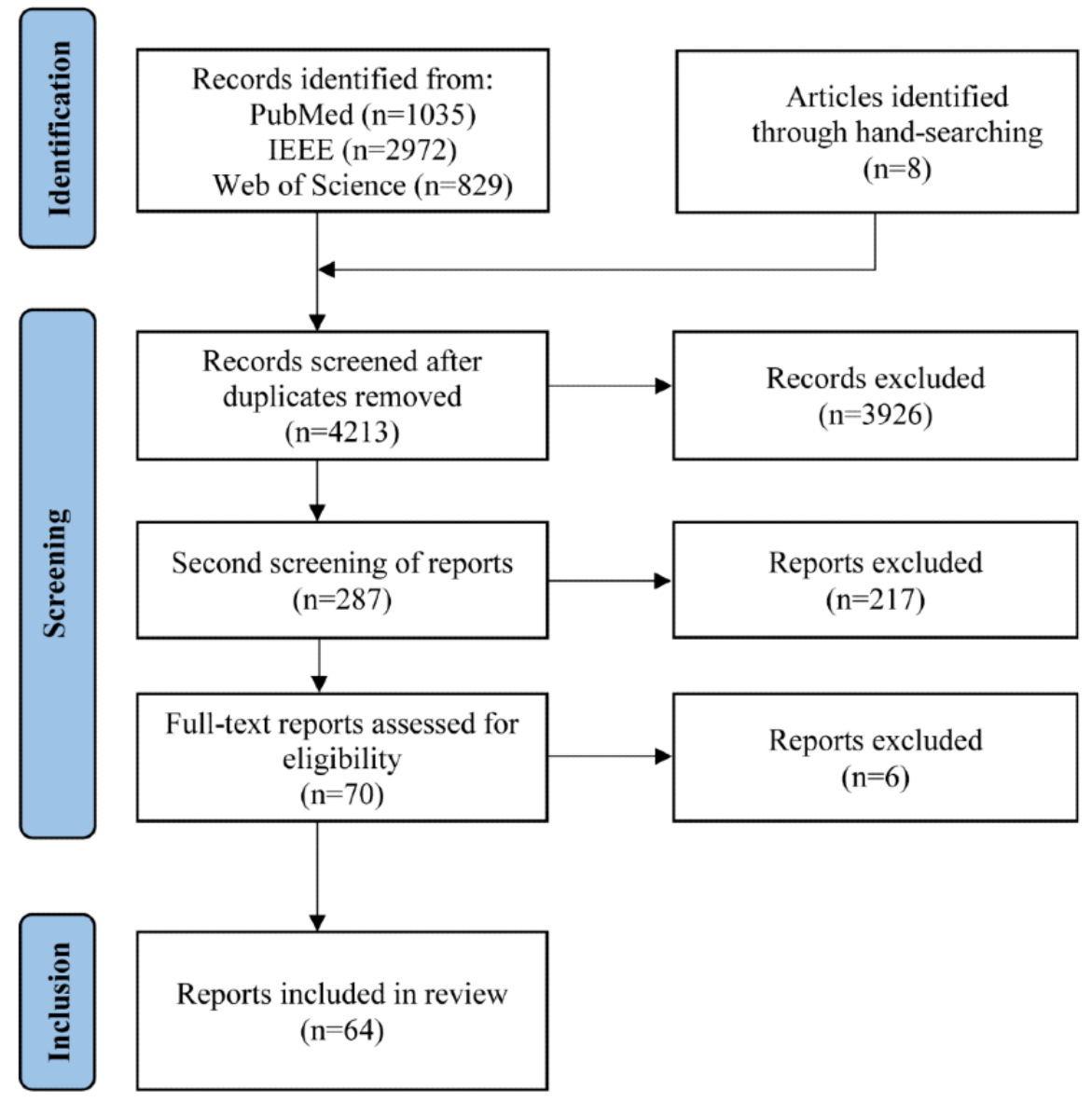

\section{Extracting Data Items}

A template for grading the reports was agreed upon by all the authors (Multimedia Appendix 2 [26]). Two researchers (LP and JWW) independently extracted information directly relevant to the scoping review question. In cases of disagreement, a consensus was reached after discussion between the 2 researchers. The compulsory data fields were test frequency and intensity range; response method; test equipment, including the type of transducers; calibration; hardware; test quality control; accuracy; reliability; efficiency; validation; and test population. In the report by Mahomed et al [24], the accuracy and reliability of manual and automated approaches demonstrated equivalent performances. Time efficiency had primarily been reported by comparing the testing times of manual and automated audiometry [27-29]. The reports on machine learning audiometry explicitly used the number of trials or stimuli needed to converge to a certain precision (eg, $5 \mathrm{~dB}$ ) as a performance outcome [23,29]. Therefore, we added time efficiency as a necessary parameter. Where available, accuracy and reliability were expressed in decibels using the overall root mean square deviation (RMSD) between the automated approach and the gold (or reasonable) standard. On the basis of the study by Margolis et al [30] and the minimum acceptable accuracy recommended by clinical guidelines [31], RMSD values of $6 \mathrm{~dB}$ and $10 \mathrm{~dB}$ were chosen as criteria for desired and minimal accuracy, respectively. To establish a benchmark for an acceptable test duration, the mean testing time for conventional manual bilateral audiometry (air 7 and bone 5 frequencies) was estimated (Multimedia Appendix 3 [27-29,31,34,38]). For manual bilateral air conduction, based on the benchmark measurement times, a mean testing time of 5 to 10 minutes was considered acceptable, and for manual bilateral air and bone conduction, 10 to 20 minutes was considered acceptable. If testing times exceeded these ranges by $>5$ minutes, the time efficiency was assessed as a potential issue.

Data collected from the reports provided key information about the scope and details of each report, enabling the authors to assess commonalities between the approaches.

\section{Collating Approaches, Summarizing, and Reporting the Results}

When multiple reports described the same underlying approach, these reports were pooled into one approach cluster. The first report describing an approach and subsequent studies that validated or extended the approach were included. The name of the approach, citations to the initial report, or common authorships were used to cluster the reports. The grading table was completed for each cluster separately to provide a structure for the subsequent content analysis. In the last part of the grading table, under the heading Validation Approach, all validation studies are described together. For every approach cluster, a key contribution to the audiological field was derived from the associated reports. A key contribution is a finding or claim made by the authors significant to the approach in general, stated in 
either the conclusion or the discussion section of a report in accordance with their objective.

\section{Results}

\section{Overview}

A total of 64 reports were included in this study. Of the 64 reports, $56(88 \%)$ were included according to the inclusion and exclusion criteria, and 8 (13\%) were added to the approach clusters. After clustering identical approaches, 27 approach clusters remained, including 2 that used machine learning. Extracted data items and grading of results on approaches are provided in Multimedia Appendix 4 [21,23,27-30,32-89]. The specifications of the reported accuracy, reliability, and time efficiency are described in Table 1.

Table 1. Review of the accuracy, test-retest reliability, and time efficiency for automated and machine learning audiometry approaches (2012-2021; $\mathrm{N}=27$ approach clusters).

\begin{tabular}{|c|c|c|c|c|c|c|}
\hline \multirow[t]{2}{*}{ Type of transducer } & \multicolumn{2}{|l|}{ Accuracy } & \multicolumn{2}{|c|}{ Reliability (test-retest) } & \multicolumn{2}{|l|}{ Time efficiency } \\
\hline & $\begin{array}{l}\text { Reported find- } \\
\text { ing }\end{array}$ & $\begin{array}{l}\text { Values, } \mathrm{n} \\
(\%)\end{array}$ & $\begin{array}{l}\text { Reported find- } \\
\text { ing }\end{array}$ & $\begin{array}{l}\text { Values, } \mathrm{n} \\
(\%)\end{array}$ & Reported finding & $\begin{array}{l}\text { Values, } \mathrm{n} \\
(\%)\end{array}$ \\
\hline
\end{tabular}

Air conduction ( $n=23$ approach clusters)

\begin{tabular}{|c|c|c|c|c|c|}
\hline $\operatorname{RMSD}^{\mathrm{a}}<6 \mathrm{~dB}^{\mathrm{b}}$ & $4(17)$ & RMSD $<6 \mathrm{~dB}$ & $4(17)$ & Acceptable testing time per (partial) audiogram & $10(43)$ \\
\hline $\mathrm{RMSD}<10 \mathrm{~dB}$ & $7(30)$ & RMSD $<10 \mathrm{~dB}$ & $1(4)$ & $\begin{array}{l}\text { Acceptable testing time and number of trials } \\
\text { per audiogram }\end{array}$ & $2(9)$ \\
\hline $\begin{array}{l}\text { Statistical } \\
\text { equivalence }\end{array}$ & $9(39)$ & $\begin{array}{l}\text { Statistical } \\
\text { equivalence }\end{array}$ & $9(39)$ & $\begin{array}{l}\text { Acceptable testing time and number of trials } \\
\text { per frequency }\end{array}$ & $1(4)$ \\
\hline $\begin{array}{l}\text { No statistical } \\
\text { equivalence }\end{array}$ & $3(13)$ & Not reported & $9(39)$ & Testing time potential burden & $1(4)$ \\
\hline$N / A^{c}$ & N/A & N/A & N/A & Not reported & $9(39)$ \\
\hline
\end{tabular}

Bone conduction ( $\mathrm{n}=1$ approach cluster)

\begin{tabular}{|c|c|c|c|c|}
\hline $\begin{array}{l}\text { Statistical } \\
\text { equivalence }\end{array}$ & $1(100)$ & Test-retest not & $1(100)$ & Not reported \\
\hline
\end{tabular}

Both air and bone conduction ( $n=3$ approach clusters)

Air conduction

$\begin{array}{llll}\text { RMSD }<6 \mathrm{~dB} & 2(67) & \mathrm{RMSD}<6 \mathrm{~dB} & 1(33) \\ \mathrm{RMSD}<10 \mathrm{~dB} & 1(33) & \mathrm{RMSD}<10 \mathrm{~dB} & 2(67)\end{array}$

Acceptable testing time per audiogram

Bone conduction

$\begin{array}{ll}\text { RMSD }<10 \mathrm{~dB} & 1(33) \\ \text { Statistical } & 2(67) \\ \text { equivalence } & \end{array}$

RMSD $<6 \mathrm{~dB}$
Test-retest not
reported

$1(33)$

N/A

N/A equivalence

2 (67)

N/A

N/A

Air and bone conduction

N/A

N/A

N/A

N/A

Acceptable testing time per audiogram

$1(33)$

${ }^{a}$ RMSD: root mean square deviation.

$\mathrm{b}_{\mathrm{dB}}$ : decibels.

${ }^{\mathrm{c}} \mathrm{N} / \mathrm{A}$ : not applicable.

\section{Accuracy}

Accuracy is represented as a comparison against the gold standard or reasonable standard. Most of the automated techniques (14/27, 52\%) expressed accuracy in RMSD. Other types of analyses used average differences and SD (10/27, 37\%), average thresholds and SD $(1 / 27,4 \%)$ [32], linear regression and correlation coefficients $(1 / 27,4 \%)$ [33], and analysis of variance $(1 / 27,4 \%)$ [34]. The types of analysis used can be seen in Multimedia Appendix 5 [23,32-37,39,40,43,45,48-50,57-59, $65,67,68,70,74,77,81,83-85]$.

\section{Test-Retest Reliability}

Test-retest reliability was reported for some automated and machine learning audiometry approaches. Of the 27 approaches, $17(63 \%)$ did not report on test-retest reliability, and 7 (26\%) expressed it in RMSD. Other statistical methods used were average differences and SD $(6 / 27,22 \%)$, Pearson product moment correlation coefficients $(2 / 27,7 \%)$ [35,36], standard of variance $(1 / 27,4 \%)$ [37], and repeated analysis of variance $(1 / 27,4 \%)$ [34]. 


\section{Test Efficiency}

Of the 27 approaches, 17 (63\%) reported a measure for test efficiency based on the test duration. Test efficiency expressed in testing time seems to be a standard metric, similar across studies and defined as the time from presenting the first stimulus until the final response of the participant, expressed in seconds or minutes. However, there were disagreement among reports on what to include in the measurement and what groups to use as a reference. Reported time-efficiency measures included the recorded time per frequency, recorded time per unilateral or bilateral air conduction audiogram (between 2 and 7 frequencies) in normal hearing or people with hearing impairment, or full air and bone conduction audiograms in people with hearing impairment. Of the 27 approach clusters, 13 (48\%) approach clusters reported acceptable testing times; 3 (11\%) approach clusters indicated the number of trials in addition to the testing time for either a bilaterally masked air audiogram [29], unilateral air audiogram [23], or per frequency [38]; 1 (4\%) approach cluster that applied Bekesy tracking reported the testing time but was not in the acceptable range [39]; and 10 (37\%) approach clusters did not report anything about the testing time.

\section{Test Parameters and Specifications}

All tests were self-administered from the point at which the test started. Approximately 15\% (4/27) of approaches had the option of switching to a manual audiometry mode. Table 2 summarizes an overview of the test parameters and specifications of the 27 approach clusters, and Table 3 highlights the key contributions. Most of the approaches used adaptive procedures that relied only on the previous response (here referred to as partially adaptive procedures).

The most common example was the (modified) Hughson-Westlake staircase procedure (20/27, 74\%), which is based on the classical method of limits [91]. Other partially adaptive procedures applied the method of adjustment, such as the Bekesy tracking method [39] or the coarse-to-fine focus algorithm [40]. There was a single report of an approach that did not define the threshold-seeking method but had a built-in protocol to alternate between ears during testing [35]. In contrast, fully adaptive procedures used a complete set of all previous responses. Examples include Bayesian active learning procedures (also referred to as machine learning audiometry; $2 / 27,7 \%)[21,23]$ and maximum likelihood estimation $(2 / 27$, $7 \%$ ) [37,38]. All machine learning audiometry methods applied active Bayesian model selection, which is a type of shallow machine learning that uses individual models. They apply supervised learning, as every data point is labeled by the participant [22].

Most of the approaches (20/27, 74\%) used conventional calibration according to the International Organization for Standardization standards. Of the 27 approaches, 6 (22\%) used an unconventional calibration technique. Patel et al [32] determined a reference equivalent threshold level for air conduction for a specific phone-headphone combination using manual audiometry as a reference. Masalski et al [41] used reference levels for calibration for smartphone and transducer combinations, collected under uncontrolled conditions in people with normal hearing. Other calibration techniques set the volume of the device to 50\% [42], comparing and adjusting the output level to the input using a sound level meter [34,43], or using Thévenin-equivalent probe calibration [39].

Of the 27 approaches, 22 (82\%) were validated in people with normal hearing and hearing impairment. Approximately $7 \%$ $(4 / 56)$ of studies were performed in people with normal hearing $[34,36,38]$. One of the approach clusters was only validated in a population with hearing impairments using hearing aids as transducers [40]. Automated audiometry was applied across a range of populations. All approaches were applied to adults, except in the study by Patel et al [32] that only included children. Approximately $30 \%(8 / 27)$ approaches were validated in children, including 50\% (4/8) of approaches that designed a child-friendly user interface [32,44-46]. Other test populations were older people [47], veterans [48], and persons exposed to occupational noise [49] or ototoxic substances [50]. Automated audiometry has also been applied as an alternative to traditional manual audiometry in low-resource environments [51-53]. The user interface plays an important role in making self-testing feasible in all populations and may require an iterative design process (including clinical pilot studies) [52,54]. 
Table 2. Description of test parameters and specifications for automated audiometry approaches (2012-2021; N=27).

Test parameters and specifications $\quad$ Descriptions of approach clusters, $\mathrm{n}(\%)$

Threshold-seeking method (underlying algorithm to determine the thresholds)

$\begin{array}{ll}\text { Hughson-Westlake (modified) } & 20(74) \\ \text { Machine learning } & 2(7) \\ \text { Bekesy tracking } & 1(4) \\ \text { Other method } & 4(15)\end{array}$

Test range (limits of the frequency that can be tested)

Clinical frequency range $(125 \mathrm{~Hz}-8000 \mathrm{~Hz}) \quad 18(67)$

Extended high frequencies range $(125 \mathrm{~Hz}-16,000 \mathrm{~Hz})$

Reduced frequency range 5 (19)

Test range (limits of intensity that can be tested)

Intensity range $\left(0-100 \mathrm{~dB}^{\mathrm{a}}\right.$ hearing level)

Reduced intensity range $10(37)$

Intensity range not reported $3(11)$

Masking (needed to prevent responses from the nontest ear and obtain the true threshold of the test ear)
Automated masking
$9(33)$
Manual masking
No masking
Masking not reported

Response method (method of recording participants' responses to test stimuli)
Forced choice
Single response
Forced choice and single response
Not reported

Transducers (method of presenting stimuli, eg, insert phone or supra- or circumaural headphones)
Air conduction transducers
$23(85)$
Air and bone conduction transducers
$3(11)$
Only bone conduction transducer

Calibration (unconventional calibration methods are explained in the text)

Conventional calibration

Unconventional calibration

Calibration not reported

Digital devices (reported hardware needed to run the test)

Portable audiometer

Computer based

Web-based (requires connectivity)

Smartphone- or tablet-based

Quality control measures (indicators of the reliability of the test)

Detect false responses

Have noise control

Detect false responses and have noise control

Quality control measures not reported

Validation (highest level of validation reported for each approach cluster) 


\begin{tabular}{ll}
\hline Test parameters and specifications & Descriptions of approach clusters, $\mathrm{n}(\%)$ \\
\hline Gold standard & $22(82)$ \\
Reasonable standard & $4(15)$ \\
Proof of concept & $1(4)$ \\
Test population (hearing status) & $3(11)$ \\
Normal hearing only & $1(4)$ \\
Hearing loss only & $23(85)$ \\
Normal hearing and hearing loss & \\
Test population (age) & $17(63)$ \\
Adults only & $1(4)$ \\
Children only & $9(33)$ \\
Adults and children & \\
\hline
\end{tabular}

a dB: decibels 
Table 3. Key contributions of the automated and machine learning approaches to the audiological field.

\begin{tabular}{|c|c|c|}
\hline $\begin{array}{l}\text { Approach cluster (lead au- } \\
\text { thor of first report, reports) }\end{array}$ & $\begin{array}{l}\text { Approach cluster } \\
\text { (name) }\end{array}$ & Key contributions to the field \\
\hline Bean et al [55] & OtoKiosk & $\begin{array}{l}\text { It has the potential to be used in test environments such as examination rooms as a clinical tool for } \\
\text { identifying hearing loss via air conduction separating people with normal and impaired hearing. }\end{array}$ \\
\hline Chen et al [40] & SHSA $^{\text {a }}$ & It is a hearing test that runs on a hearing aid, which has statistical equivalence to manual audiometry. \\
\hline Colsman et al [36] & $-\mathrm{b}$ & $\begin{array}{l}\text { Portable devices that use calibrated headphones result in much higher accuracies than uncalibrated } \\
\text { devices. }\end{array}$ \\
\hline Corry et al [34] & - & $\begin{array}{l}\text { The reliability of audiometer apps should not be assumed. Issues of accuracy and calibration of } \\
\text { consumer headphones need to be addressed before such combinations can be used with confidence. }\end{array}$ \\
\hline Dewyer et al [33] & Earbone & It is a proof of concept for smartphone-based bone conduction threshold testing. \\
\hline Foulad et al $[43,51,56]$ & Eartrumpet & $\begin{array}{l}\text { It is an iOS-based software app for automated pure-tone hearing testing without the need for addi- } \\
\text { tional specialized equipment, yielding hearing test results that approach those of conventional au- } \\
\text { diometry. }\end{array}$ \\
\hline Jacobs et al $[50,57]$ & Oto-ID & $\begin{array}{l}\text { They are automated (remote) hearing tests to provide clinicians information for ototoxicity monitor- } \\
\text { ing. }\end{array}$ \\
\hline Kung et al [45] & $\begin{array}{l}\text { Kids Hearing } \\
\text { Game }\end{array}$ & $\begin{array}{l}\text { It includes tablet-based audiometry using game design elements that can be used to test and screen } \\
\text { for hearing loss in children who may not have adequate access to resources for a traditional hearing } \\
\text { screening. }\end{array}$ \\
\hline Liu et al [58] & - & $\begin{array}{l}\text { A self-testing system comprising a notebook computer, sound card, and insert earphones is a valid, } \\
\text { portable, and sensitive instrument for hearing thresholds self-assessment. }\end{array}$ \\
\hline Manganella et al [35] & Agilis & $\begin{array}{l}\text { It is an application that detects increased levels of ambient noise when it is programmed to stop the } \\
\text { testing. }\end{array}$ \\
\hline Margolis et al [30,46,59-61] & AMTAS $^{\mathrm{c}}$ & $\begin{array}{l}\text { AMTAS is designed to fit into the clinical care pathway, including air and bone conduction, and } \\
\text { incorporates a quality assessment method (QUALIND) that predicts the accuracy of the test. }\end{array}$ \\
\hline Margolis et al $[48,62,63]$ & $\begin{array}{l}\text { Home Hearing } \\
\text { Test }\end{array}$ & $\begin{array}{l}\text { It is developed and well-suited to provide increased access to hearing testing and support home } \\
\text { telehealth programs. }\end{array}$ \\
\hline $\begin{array}{l}\text { Masalski and Krecicki } \\
{[41,64,65]}\end{array}$ & - & $\begin{array}{l}\text { It is an automated method that uses smartphone model-specific reference sound levels for calibration } \\
\text { in the app. Biological reference sound levels were collected in uncontrolled conditions in people } \\
\text { with normal hearing. }\end{array}$ \\
\hline Meinke et al $[66,67]$ & WHATS $^{\mathrm{d}}$ & $\begin{array}{l}\text { WHATS is a mobile wireless automated hearing test system in occupational audiometry for obtaining } \\
\text { hearing thresholds in diverse test locations without the use of a sound booth. }\end{array}$ \\
\hline Patel et al [32] & HearTest ${ }^{\mathrm{e}}$ & $\begin{array}{l}\text { It is a novel, subjective, test-based approach used to calibrate a smartphone-earphone combination } \\
\text { with respect to the reference audiometer. }\end{array}$ \\
\hline Poling et al [39] & - & $\begin{array}{l}\text { Specific Bekesy tracking patterns were identified in people who experienced difficulty converging } \\
\text { to a reliable threshold. }\end{array}$ \\
\hline Schlittenlacher et al [23] & - & $\begin{array}{l}\text { Bayesian active learning methods provide an accurate estimate of hearing thresholds in a continuous } \\
\text { range of frequencies. }\end{array}$ \\
\hline Schmidt et al [37] & - & $\begin{array}{l}\text { A user-operated, 2-alternative, forced choice in combination with the method of maximum likelihood } \\
\text { does not require specific operating skills; repeatability is acceptable and is similar to conventional } \\
\text { audiometry. }\end{array}$ \\
\hline Song et al $[21,29,68,69]$ & $M_{L A G}{ }^{f}$ & $\begin{array}{l}\text { MLAG is a Bayesian active learning method that determines the most informative next tone, leading } \\
\text { to a fast audiogram procedure and threshold estimation in a continuous range of frequencies, with } \\
\text { the potential to measure additional variables efficiently. }\end{array}$ \\
\hline Sun et al [70] & - & It is an active noise control technology to measure outside the sound booth. \\
\hline $\begin{array}{l}\text { Swanepoel et al } \\
{[27,47,53,71-75]}\end{array}$ & KUDUwave & $\begin{array}{l}\text { It is an automated portable diagnostic audiometer using improved passive attenuation and real-time } \\
\text { environmental noise monitoring, making audiometry possible in unconventional settings. }\end{array}$ \\
\hline $\begin{array}{l}\text { Swanepoel et al } \\
{[28,52,54,76-80]}\end{array}$ & HearTest ${ }^{\mathrm{g}}$ & It is a smartphone-based automated hearing test applicable in low-resource environments. \\
\hline Szudek et al $[42,81,82]$ & Uhear & $\begin{array}{l}\text { It is an approach that is applicable to the initial evaluation of patients with sudden sensorineural } \\
\text { hearing loss before a standard audiogram is available. }\end{array}$ \\
\hline $\begin{array}{l}\text { Van Tasell and Folkeard } \\
\text { [83] }\end{array}$ & - & $\begin{array}{l}\text { Method of adjustment and the Hughson-Westlake method embedded in automated audiometry can } \\
\text { be considered equivalent in accuracy to conventional audiometry. }\end{array}$ \\
\hline
\end{tabular}




\begin{tabular}{lll}
\hline $\begin{array}{l}\text { Approach cluster (lead au- } \\
\text { thor of first report, reports) }\end{array}$ & $\begin{array}{l}\text { Approach cluster } \\
\text { (name) }\end{array}$ & Key contributions to the field \\
\hline Vinay et al [38,49] & NEWT & $\begin{array}{l}\text { NEWT, which is incorporated inside an active communication earplug, serves as a reliable and ef- } \\
\text { ficient method of measuring auditory thresholds, especially in the presence of high background } \\
\text { noise. }\end{array}$ \\
Whitton et al [84] & $\begin{array}{l}\text { It is a proof-of-concept study of several self-administered, automated hearing measurements at } \\
\text { home, showing statistical equivalency to conventional audiometry in the clinic. }\end{array}$ \\
Yeung et al [44,85-89] & Shoebox & $\begin{array}{l}\text { It is a method for threshold hearing assessments outside conventional sound booths and with an in- } \\
\text { terface suitable for children. }\end{array}$ \\
\hline
\end{tabular}

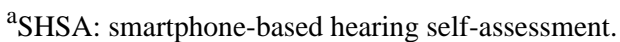

${ }^{b}$ Not available.

${ }^{\mathrm{c}}$ AMTAS: Automated Method for Testing Auditory Sensitivity.

${ }^{\mathrm{d}}$ WHATS: Wireless Automated Hearing Test System.

${ }^{\mathrm{e}}$ Smartphone-based hearing test app (not yet commercialized).

${ }^{f}$ MLAG: Machine Learning Audiogram.

g Automated hearing test commercialized by the hearX group.

${ }^{h}$ NEWT: The New Early Warning Test.

\section{Discussion}

\section{Principal Findings}

In 2013, evidence for automated audiometry demonstrated similar reliability and accuracy as that of manual audiometry. However, especially for children and bone conduction, the number of reports was limited [24]. In less than a decade, 22 novel approaches and developments across 5 existing approaches had appeared in 56 publications, adding to the 29 papers published before 2013. Promising new developments include the use of machine learning techniques for more time-efficient hearing assessment $(2 / 27,7 \%)$, use of tablets or smartphones as audiometer interface $(15 / 27,56 \%)$, and child-friendly user interfaces $(4 / 27,15 \%)$, including game design elements. The number of approaches that include bone conduction is still limited $(4 / 27,15 \%)$ —only $7 \%$ (2/29) more approaches were reported compared with the number reported in 2013 [24].

\section{Accuracy}

The required accuracy, reliability, and efficiency depend on the clinical aims and consequences. The ultimate aim of the automated hearing assessment is to deliver clinically actionable estimates of hearing status (ie, the clinician or patient acts appropriately for treatment, given the diagnostic test results). In fully adaptive procedures, the level of precision and confidence needed to conclude the assessment can be set to any level by choosing the proper termination criteria, resulting in different trade-offs. A study by Schmidt et al [37], for instance, aimed for high accuracy and reliability, whereas a study by Heisey et al [29] aimed for high efficiency with machine learning audiometry. Overall, a shift in the type of analysis to demonstrate the accuracy has been observed. In this review, the 2 major types of analysis included were RMSD (14/27, 52\%) and average differences and SD $(10 / 27,37 \%)$. In the report by Mahomed et al [24], accuracy was primarily expressed in average differences $(11 / 27,41 \%)$ or thresholds and SD (11/27, $41 \%$ ). In our view, RMSD is the preferred indicator for accuracy as it has clinical relevance [31], assuming it has already been demonstrated that there is no bias between the automated and manually determined hearing thresholds (eg, signed differences). In traditional clinical terms, automation is equal in accuracy to manual audiometry if the difference is within $6 \mathrm{~dB}$ RMSD. Of the 27 automated approaches, $6(22 \%)$ meet this strict accuracy criterion. However, for many applications, the less strict $10 \mathrm{~dB}$ RMSD criterium is sufficient, which was achieved by $26 \%$ (7/27) additional automated approaches.

For bone conduction measurements, the accuracy was inherently lower than that of air conduction measurements because of conductor placement [30]. However, this reduced accuracy is typically sufficient to address the clinical question of whether conductive or mixed hearing loss is present, as well as choose and evaluate appropriate treatment. The technical feasibility of bone conduction assessments outside of a clinical setting (sound booth) remains difficult. Alternatively, this clinical question can be addressed with other tests, including tympanometry, otoscopy, or a combination of air conduction thresholds for tone and speech stimuli [90]. At least 13 automated techniques had accuracy comparable with that of traditional manual air conduction audiometry, as expressed in RMSD.

A limitation to the impact of achieved test accuracy is the high variation in the interpretation of audiograms by clinicians, regardless of whether those audiograms are determined using an automated or manual approach [92]. Automation can assist clinicians and patients in interpreting the measurement by data-driven automated reporting of accuracy and reliability (including signaling for suspicious outcomes) such as QUALIND [60] or by automated classification for diagnostic purposes (including the type and degree of hearing loss). Examples of automated classification include AMCLASS [93], Autoaudio [94], and data-driven audiogram classification [95].

\section{Reliability}

RMSD is also increasingly used as a measure of test-retest reliability. Of the 27 approaches that reported test-retest reliability, $8(30 \%)$ used RMSD as a measure, whereas in 2013, this was only used in $2(2 / 29,7 \%)$ studies. Furthermore, $41 \%$ $(11 / 27)$ of approaches did not report on test-retest reliability or used a measure of statistical equivalence that did not allow us 
to assess the accuracy. Advances in automated audiometry that increase reliability include procedures to identify invalid responses $(5 / 27,19 \%)$, monitoring environmental noise $(6 / 27$, $22 \%)$, or both $(7 / 27,26 \%)$ to warn for invalid test conditions, making these tests applicable in more populations and environments. The reliability can be increased, for instance, by alternative response methods, including the forced-choice paradigm [37], or by using machine learning to account for lapses of attention [23]. Digital (health) technologies, including smartphones and tablets, lend themselves to quality control measures for increased reliability with the host of integrated sensors [6].

\section{Efficiency}

A fair indicator of efficiency is the overall time required to conduct a test. Most approaches $(20 / 27,74 \%)$ used the modified Hughson-Westlake procedure, of which some (7/20, 35\%) showed a similar test duration to manual audiometry. Maximum likelihood procedures demonstrated a $45 \%$ reduction in test time in people with normal hearing [38]. Bayesian active learning methods can be extended by adding variables that share some interrelationships using a conjoint estimator that exploits nonlinear interactions between the variables [96]. The resulting machine learning-based automated procedures demonstrated a $30 \%$ to $70 \%$ reduction in test time compared with manual audiometry for air conduction audiograms in people with normal hearing and hearing impairment [29]. No machine learning approaches had incorporated bone conduction. Therefore, time-efficiency gains compared with full audiogram procedures are not available; however, one can assume that these will yield similar time-efficiency gains. Another indicator of test efficiency is the number of stimuli required to achieve the desired accuracy. This indicator is helpful in optimizing the threshold-seeking part of the approach. Reporting the equivalent time gains under operational conditions is recommended as this can be readily compared with other efficiency gains, including the reduced traveling time if a visit to the outpatient clinic can be replaced for an at-home test or time savings by automating other parts of the clinical care pathway such as interpretation of the outcome. Other aspects of efficiency beyond time that should be considered are cost reductions when enabling task shifting of professionals or the ability to test outside the sound booth.

\section{Future Developments}

To obtain an overall indicator of the technical maturity of an approach, developers should be encouraged to use the technology readiness level (TRL) to report the development phase of a technology. TRLs were initially developed in the aerospace industry to estimate the maturity of technology from basic concepts to flight-proven products [97]. To apply TRLs to automated audiometry, further adjustments can be made to fit the hearing health care sector to the version of biomedical TRLs created by the US Army Medical Research and Materiel Command [98]. For those approaches that are ready for operational use, certification (eg, Conformité Européenne and the United States Food and Drug Administration) can further stimulate clinical adoption and iterative improvements based on clinical feedback. In order to be cost-effective, timely, and responsive, certification for digital self-care approaches may need to be less stringent than those for clinical care. A study by Yeung et al [12] proposed alternative procedures for (fast) certification to keep up with the rapidly developing field of visual eHealth tools. Their recommendations might also be applicable to automated hearing assessments, including a rating by health agencies or nongovernmental organizations (eg, a repository of trusted approaches; see Psyberguide [99] as an example of mental health apps reviewed by experts) or adopting the Clinical Laboratory Improvement Amendments model to ensure that approaches comply with the basic requirements of usability, privacy, and security [12]. Following similar certification procedures in the visual and auditory domains may facilitate diagnosis across medical domains. In addition, standards on minimum quality and consensus on what metadata are needed in health applications to describe the test conditions and facilitate interpretation are currently missing.

\section{Limitations}

This scoping review included peer-reviewed reports from widely used and recognized scientific databases. A potential limitation is that some of the commercialized automated approaches may have been developed without peer-reviewed reports. Therefore, some automated approaches could be more mature than previously reported. There is no gold standard for reporting audiometry validation studies, which limits a consistent comparison among approaches. Finally, automated procedures may well be embraced by early adopters first, which could lead to projections on suitability that are overly optimistic for users with poorer digital proficiency.

\section{Conclusions and Recommendations}

Since 2013, an increasing number of automated audiometry approaches on digital devices have demonstrated similar accuracy, reliability, and time efficiency as conventional manual audiometry. New developments offer features, versatility, and cost-effectiveness beyond manual audiometry. Fully adaptive procedures, including machine learning techniques, seek hearing thresholds more efficiently. Inexpensive digital devices such as smartphones can be turned into audiometers, increasing accessibility and availability. Higher reliability is achievable by signaling invalid test conditions, and child-friendly user interfaces offer a solution to the hard-to-test population. These approaches can be implemented in the clinical care pathway, remote or virtual hearing health care, community-based services, and occupational health care to address the global need for accessible hearing loss diagnosis.

For successful adoption, standardized measures of accuracy, reliability, and efficiency are needed for comparative purposes. Certification and independent reviews may help prospective users select trustworthy approaches. Further reliability can be achieved by determining which difficult-to-test populations may not be appropriate for automated testing and how to detect and then triage these patients to specialized centers. More user-friendly and failsafe procedures that include remote surveillance and quality control can support automated hearing assessment at scale in specific populations and in concert with diagnostic assessments in other medical domains, including visual health and mental well-being [12,99]. Further contextual information, such as standardized metadata, is needed to help 
clinicians interpret the context and limitations of test outcomes. If researchers and clinicians deal carefully with their limitations, automated hearing assessments can be designed such that they form an effective part of service delivery for many people who have or are at risk of hearing loss. Automated audiometry can be part of existing care pathways and also enable new service models, including task shifting to community health workers delivering decentralized care, virtual hearing health care, and over-the-counter or direct-to-consumer hearing aid dispensing.

\section{Acknowledgments}

The authors would like to thank On Ying Chan for her help during the development of the search string and Raul Sanchez-Lopez for his comments on the draft versions of the paper. In addition, the authors would like to thank Cris P Lanting and Lucas Mens for their suggestions over the course of this study.

\section{Authors' Contributions}

LP and JWW made equal contributions, shared first authorship, conducted the abstract screening, independently extracted information directly relevant to the scoping review question, and drafted the manuscript. LP, JWW, and DWS conceptualized the study. RE and DWS supervised the study, reviewed the results, and edited the manuscript. All authors contributed to the data interpretation.

\section{Conflicts of Interest}

DWS has a relationship with the hearX Group (Pty) Ltd, which includes equity, consulting, and potential royalties. DWS holds a patent for smartphone-based audiometry as an inventor.

\section{Multimedia Appendix 1}

Search strategy.

[DOCX File, 14 KB-Multimedia Appendix 1]

\section{Multimedia Appendix 2}

Template table for grading approaches.

[DOCX File, 17 KB-Multimedia Appendix 2]

\section{Multimedia Appendix 3}

Estimated mean testing time for conventional manual bilateral audiometry.

[DOCX File , $31 \mathrm{~KB}-$ Multimedia Appendix 3]

\section{Multimedia Appendix 4}

Graded approaches.

[DOCX File, 188 KB-Multimedia Appendix 4]

\section{Multimedia Appendix 5}

Types of statistical analyses for accuracy and reliability. [DOCX File , 46 KB-Multimedia Appendix 5]

\section{References}

1. Haile LM, Kamenov K, Briant PS, Orji AU, Steinmetz JD, Abdoli A, et al. Hearing loss prevalence and years lived with disability, 1990-2019: findings from the Global Burden of Disease Study 2019. Lancet 2021 Mar;397(10278):996-1009. [doi: 10.1016/s0140-6736(21)00516-x]

2. World report on hearing. World Health Organization. 2021. URL: https://www.who.int/publications-detail-redirect/ world-report-on-hearing [accessed 2022-01-13]

3. Kamenov K, Martinez R, Kunjumen T, Chadha S. Ear and hearing care workforce: current status and its implications. Ear Hear 2021 Jan 21;42(2):249-257. [doi: 10.1097/AUD.0000000000001007] [Medline: 33480624]

4. Rajkomar A, Dean J, Kohane I. Machine learning in medicine. N Engl J Med 2019 Apr 04;380(14):1347-1358. [doi: 10.1056/nejmra1814259]

5. Wasmann J, Lanting C, Huinck W, Mylanus E, van der Laak JW, Govaerts P, et al. Computational audiology: new approaches to advance hearing health care in the digital age. Ear Hear 2021;42(6):1499-1507 [FREE Full text] [doi:

10.1097/AUD.0000000000001041] [Medline: 33675587] 
6. Taylor K, Staunton H, Lipsmeier F, Nobbs D, Lindemann M. Outcome measures based on digital health technology sensor data: data- and patient-centric approaches. NPJ Digit Med 2020;3:97 [FREE Full text] [doi: 10.1038/s41746-020-0305-8] [Medline: 32715091]

7. Swanepoel DW, De Sousa KC, Smits C, Moore DR. Mobile applications to detect hearing impairment: opportunities and challenges. Bull World Health Organ 2019 Sep 03;97(10):717-718. [doi: 10.2471/blt.18.227728]

8. Diagnostics for better health: considerations for global implementation. World Economic Forum - Insight Report. 2021. URL: http://www3.weforum.org/docs/ WEF Diagnostics for Better Health Considerations for Globa \%20Implementation 2021.pdf [accessed 2022-01-13]

9. Bloem BR, Marks WJ, Silva de Lima AL, Kuijf ML, van Laar T, Jacobs BPF, et al. The Personalized Parkinson Project: examining disease progression through broad biomarkers in early Parkinson's disease. BMC Neurol 2019 Jul 17;19(1):160 [FREE Full text] [doi: 10.1186/s12883-019-1394-3] [Medline: $\underline{\text { 31315608] }}$

10. Gatsios D, Antonini A, Gentile G, Marcante A, Pellicano C, Macchiusi L, et al. Feasibility and utility of mhealth for the remote monitoring of parkinson disease: ancillary study of the PD_manager randomized controlled trial. JMIR Mhealth Uhealth 2020 Jun 29;8(6):e16414 [FREE Full text] [doi: 10.2196/16414] [Medline: 32442154]

11. Philipsen RH, Sánchez CI, Melendez J, Lew WJ, van Ginneken B. Automated chest X-ray reading for tuberculosis in the Philippines to improve case detection: a cohort study. Int J Tuberc Lung Dis 2019 Jul 01;23(7):805-810. [doi:

10.5588/ijtld.18.0004] [Medline: $\underline{31439111]}$

12. Yeung WK, Dawes P, Pye A, Charalambous A, Neil M, Aslam T, et al. eHealth tools for the self-testing of visual acuity: a scoping review. Npj Digit Med 2019 Aug 22;2(1):1-7. [doi: 10.1038/s41746-019-0154-5]

13. Wilson BS, Tucci DL, Merson MH, O'Donoghue GM. Global hearing health care: new findings and perspectives. Lancet 2017 Dec;390(10111):2503-2515. [doi: 10.1016/s0140-6736(17)31073-5]

14. McDaid D, Park A, Chadha S. Estimating the global costs of hearing loss. Int J Audiol 2021 Mar 16;60(3):162-170. [doi: 10.1080/14992027.2021.1883197] [Medline: 33590787]

15. Tsimpida D, Kontopantelis E, Ashcroft D, Panagioti M. Conceptual Model of Hearing Health Inequalities (HHI Model): a critical interpretive synthesis. Trends Hear 2021;25:23312165211002963 [FREE Full text] [doi: 10.1177/23312165211002963] [Medline: $\underline{\text { 34049470] }}$

16. Livingston G, Sommerlad A, Orgeta V, Costafreda SG, Huntley J, Ames D, et al. Dementia prevention, intervention, and care. Lancet 2017 Dec;390(10113):2673-2734. [doi: 10.1016/S0140-6736(17)31363-6]

17. Manchaiah V, Eikelboom RH, Bennett RJ, Swanepoel DW. International survey of audiologists during the COVID-19 pandemic: effects on the workplace. Int J Audiol 2021 Jun 17:1-8. [doi: 10.1080/14992027.2021.1937348] [Medline: 34137644]

18. Saunders GH, Roughley A. Audiology in the time of COVID-19: practices and opinions of audiologists in the UK. Int J Audiol 2021 Apr;60(4):255-262. [doi: 10.1080/14992027.2020.1814432] [Medline: 32909474]

19. Eksteen S, Launer S, Kuper H, Eikelboom RH, Bastawrous A, Swanepoel DW. Hearing and vision screening for preschool children using mobile technology, South Africa. Bull World Health Organ 2019 Jun 19;97(10):672-680. [doi: 10.2471/blt.18.227876]

20. Békésy GV. A new audiometer. Acta Oto-Laryngologica 2009 Jul 08;35(5-6):411-422. [doi: 10.3109/00016484709123756]

21. Barbour D, Howard R, Song X, Metzger N, Sukesan K, DiLorenzo J, et al. Online machine learning audiometry. Ear Hear 2019;40(4):918-926 [FREE Full text] [doi: 10.1097/AUD.0000000000000669] [Medline: 30358656]

22. Gardner J, Malkomes G, Garnett R, Weinberger K, Barbour D, Cunningham J. Bayesian active model selection with an application to automated audiometry. NeurIPS Proceedings. 2015. URL: https://proceedings.neurips.cc/paper/2015/hash/ d9731321ef4e063ebbee79298fa36f56-Abstract.html [accessed 2022-01-13]

23. Schlittenlacher J, Turner RE, Moore BC. Audiogram estimation using Bayesian active learning. J Acoust Soc Am 2018 Jul;144(1):421-430. [doi: 10.1121/1.5047436] [Medline: 30075695]

24. Mahomed F, Swanepoel D, Eikelboom R, Soer M. Validity of automated threshold audiometry: a systematic review and meta-analysis. Ear Hear 2013;34(6):745-752. [doi: 10.1097/01.aud.0000436255.53747.a4] [Medline: 24165302]

25. Arksey H, O'Malley L. Scoping studies: towards a methodological framework. Int J Soc Res Methodol 2005 Feb;8(1):19-32. [doi: 10.1080/1364557032000119616]

26. Souza NN, Dhar S, Neely ST, Siegel JH. Comparison of nine methods to estimate ear-canal stimulus levels. J Acoust Soc Am 2014 Oct;136(4):1768-1787 [FREE Full text] [doi: 10.1121/1.4894787] [Medline: 25324079]

27. Swanepoel DW, Mngemane S, Molemong S, Mkwanazi H, Tutshini S. Hearing assessment-reliability, accuracy, and efficiency of automated audiometry. Telemed J E Health 2010 Jun;16(5):557-563. [doi: 10.1089/tmj.2009.0143] [Medline: 20575723]

28. van Tonder J, Swanepoel DW, Mahomed-Asmail F, Myburgh H, Eikelboom RH. Automated smartphone threshold audiometry: validity and time efficiency. J Am Acad Audiol 2017 Mar 26;28(3):200-208. [doi: 10.3766/jaaa.16002] [Medline: 28277211]

29. Heisey K, Walker A, Xie K, Abrams J, Barbour D. Dynamically masked audiograms with machine learning audiometry. Ear Hear 2020;41(6):1692-1702 [FREE Full text] [doi: 10.1097/AUD.0000000000000891] [Medline: 33136643 ] 
30. Margolis RH, Glasberg BR, Creeke S, Moore BC. AMTAS: automated method for testing auditory sensitivity: validation studies. Int J Audiol 2010 Mar;49(3):185-194. [doi: 10.3109/14992020903092608] [Medline: 20109081]

31. Guidelines for manual pure-tone threshold audiometry. American Speech-Language-Hearing Association. 2005. URL: https://www.asha.org/policy/g12005-00014/ [accessed 2022-01-14]

32. Patel K, Thibodeau L, McCullough D, Freeman E, Panahi I. Development and pilot testing of smartphone-based hearing test application. Int J Environ Res Public Health 2021 May 21;18(11) [FREE Full text] [doi: 10.3390/ijerph18115529] [Medline: $\underline{34064080]}$

33. Dewyer NA, Jiradejvong P, Lee DS, Kemmer JD, Sabes JH, Limb CJ. Automated smartphone audiometry: a preliminary validation of a bone-conduction threshold test app. Ann Otol Rhinol Laryngol 2019 Jun 11;128(6):508-515. [doi: 10.1177/0003489419828770] [Medline: 30744390]

34. Corry M, Sanders M, Searchfield G. The accuracy and reliability of an app-based audiometer using consumer headphones: pure tone audiometry in a normal hearing group. Int J Audiol 2017 Sep;56(9):706-710. [doi: 10.1080/14992027.2017.1321791] [Medline: 28485673]

35. Manganella JL, Stiles DJ, Kawai K, Barrett DL, O'Brien LB, Kenna MA. Validation of a portable hearing assessment tool: Agilis Health Mobile Audiogram. Int J Pediatr Otorhinolaryngol 2018 Oct;113:94-98. [doi: 10.1016/j.ijporl.2018.04.010] [Medline: 30174018 ]

36. Colsman A, Supp GG, Neumann J, Schneider TR. Evaluation of accuracy and reliability of a mobile screening audiometer in normal hearing adults. Front Psychol 2020 Apr 29;11:744 [FREE Full text] [doi: 10.3389/fpsyg.2020.00744] [Medline: 32411050]

37. Schmidt JH, Brandt C, Pedersen ER, Christensen-Dalsgaard J, Andersen T, Poulsen T, et al. A user-operated audiometry method based on the maximum likelihood principle and the two-alternative forced-choice paradigm. Int J Audiol $2014 \mathrm{Jun}$ 10;53(6):383-391. [doi: 10.3109/14992027.2013.879339] [Medline: 24512274]

38. Vinay SN, Svensson UP, Kvaløy O, Berg T. A comparison of test-retest variability and time efficiency of auditory thresholds measured with pure tone audiometry and new early warning test. Appl Acoust 2015 Apr;90:153-159. [doi: 10.1016/j.apacoust.2014.11.002]

39. Poling G, Kunnel T, Dhar S. Comparing the accuracy and speed of manual and tracking methods of measuring hearing thresholds. Ear Hear 2016;37(5):336-340 [FREE Full text] [doi: 10.1097/AUD.0000000000000317] [Medline: 27232075]

40. Chen F, Wang S, Li J, Tan H, Jia W, Wang Z. Smartphone-based hearing self-assessment system using hearing aids with fast audiometry method. IEEE Trans Biomed Circuits Syst 2019:170-179. [doi: 10.1109/tbcas.2018.2878341]

41. Masalski M, Kipiński L, Grysiński T, Kręcicki T. Hearing tests on mobile devices: evaluation of the reference sound level by means of biological calibration. J Med Internet Res 2016 May 30;18(5):e130 [FREE Full text] [doi: 10.2196/jmir.4987] [Medline: 27241793]

42. Szudek J, Ostevik A, Dziegielewski P, Robinson-Anagor J, Gomaa N, Hodgetts B, et al. Can Uhear me now? Validation of an iPod-based hearing loss screening test. J Otolaryngol Head Neck Surg 2012 Apr;41 Suppl 1:78-84. [Medline: 22569055]

43. Foulad A, Bui P, Djalilian H. Automated audiometry using apple iOS-based application technology. Otolaryngol Head Neck Surg 2013 Nov 20;149(5):700-706. [doi: 10.1177/0194599813501461] [Medline: 23963611]

44. Yeung JC, Heley S, Beauregard Y, Champagne S, Bromwich MA. Self-administered hearing loss screening using an interactive, tablet play audiometer with ear bud headphones. Int J Pediatr Otorhinolaryngol 2015 Aug;79(8):1248-1252. [doi: 10.1016/j.ijporl.2015.05.021] [Medline: 26055197]

45. Kung B, Kunda L, Groff S, Miele E, Loyd M, Carpenter DM. Validation Study of Kids Hearing Game: A Self-Administered Pediatric Audiology Application. Perm J 2021 May;25. [doi: 10.7812/TPP/20.157] [Medline: 33970081]

46. Margolis R, Frisina R, Walton J. AMTAS(®): automated method for testing auditory sensitivity: II. air conduction audiograms in children and adults. Int J Audiol 2011 Jul;50(7):434-439. [doi: 10.3109/14992027.2011.553206] [Medline: 21417674]

47. Maclennan-Smith F, Swanepoel DW, Hall JW. Validity of diagnostic pure-tone audiometry without a sound-treated environment in older adults. Int J Audiol 2013 Feb 11;52(2):66-73. [doi: 10.3109/14992027.2012.736692] [Medline: 23140522]

48. Margolis RH, Killion MC, Bratt GW, Saly GL. Validation of the Home Hearing Test ${ }^{\mathrm{TM}}$. J Am Acad Audiol 2016 May 06;27(5):416-420. [doi: 10.3766/jaaa.15102] [Medline: 27179261]

49. Henriksen V, Kvaløy O, Svensson UP. Development and calibration of a new automated method to measure air conduction auditory thresholds using an active earplug. Acta Acust United Acust 2014 Jan 01;100(1):113-117. [doi: 10.3813/aaa.918691]

50. Jacobs PG, Silaski G, Wilmington D, Gordon S, Helt W, McMillan G, et al. Development and evaluation of a portable audiometer for high-frequency screening of hearing loss from ototoxicity in homes/clinics. IEEE Trans Biomed Eng 2012 Nov;59(11):3097-3103. [doi: 10.1109/tbme.2012.2204881]

51. Kelly E, Stadler M, Nelson S, Runge C, Friedland DR. Tablet-based screening for hearing loss: feasibility of testing in nonspecialty locations. Otol Neurotol 2018 Apr;39(4):410-416. [doi: 10.1097/MAO.0000000000001752] [Medline: 29494473]

52. Sandström J, Swanepoel D, Laurent C, Umefjord G, Lundberg T. Accuracy and reliability of smartphone self-test audiometry in community clinics in low income settings: a comparative study. Ann Otol Rhinol Laryngol 2020 Jun;129(6):578-584. [doi: $10.1177 / 0003489420902162]$ [Medline: $\underline{31965808}$ ] 
53. Visagie A, Swanepoel DW, Eikelboom RH. Accuracy of remote hearing assessment in a rural community. Telemed J E Health 2015 Nov;21(11):930-937. [doi: 10.1089/tmj.2014.0243] [Medline: 26076335]

54. Sandström J, Swanepoel DW, Myburgh HC, Laurent C. Smartphone threshold audiometry in underserved primary health-care contexts. Int J Audiol 2016 Jan 21;55(4):232-238. [doi: 10.3109/14992027.2015.1124294] [Medline: 26795898]

55. Bean BN, Roberts RA, Picou EM, Angley GP, Edwards AJ. Automated audiometry in quiet and simulated exam room noise for listeners with normal hearing and impaired hearing. J Am Acad Audiol 2021 May 25. [doi: 10.1055/s-0041-1728778] [Medline: 34034339]

56. Saliba J, Al-Reefi M, Carriere JS, Verma N, Provencal C, Rappaport JM. Accuracy of mobile-based audiometry in the evaluation of hearing loss in quiet and noisy environments. Otolaryngol Head Neck Surg 2017 Apr 27;156(4):706-711. [doi: 10.1177/0194599816683663] [Medline: 28025906]

57. Dille MF, Jacobs PG, Gordon SY, Helt WJ, McMillan GP. OtoID: new extended frequency, portable audiometer for ototoxicity monitoring. J Rehabil Res Dev 2013;50(7):997-1006 [FREE Full text] [doi: 10.1682/JRRD.2012.09.0176] [Medline: 24301436]

58. Liu Y, Yang D, Xiong F, Yu L, Ji F, Wang Q. Development and validation of a portable hearing self-testing system based on a notebook personal computer. J Am Acad Audiol 2015 Sep 06;26(8):716-723. [doi: 10.3766/jaaa.14092] [Medline: 26333879]

59. Eikelboom RH, Swanepoel DW, Motakef S, Upson GS. Clinical validation of the AMTAS automated audiometer. Int J Audiol 2013 May 03;52(5):342-349. [doi: 10.3109/14992027.2013.769065] [Medline: 23548148]

60. Margolis RH, Saly GL, Le C, Laurence J. Qualind: a method for assessing the accuracy of automated tests. J Am Acad Audiol 2007 Jan;18(1):78-89. [doi: 10.3766/jaaa.18.1.7] [Medline: 17252960 ]

61. Margolis R, Moore B. AMTAS(®): automated method for testing auditory sensitivity: III. sensorineural hearing loss and air-bone gaps. Int J Audiol 2011 Jul;50(7):440-447. [doi: 10.3109/14992027.2011.575085] [Medline: 21668325]

62. Margolis RH, Bratt G, Feeney MP, Killion MC, Saly GL. Home hearing test: within-subjects threshold variability. Ear Hear 2018;39(5):906-909 [FREE Full text] [doi: 10.1097/AUD.0000000000000551] [Medline: 29356703]

63. Mosley CL, Langley LM, Davis A, McMahon CM, Tremblay KL. Reliability of the home hearing test: implications for public health. J Am Acad Audiol 2019 Mar;30(3):208-216 [FREE Full text] [doi: 10.3766/jaaa.17092] [Medline: 30461396]

64. Masalski M, Kręcicki T. Self-test web-based pure-tone audiometry: validity evaluation and measurement error analysis. J Med Internet Res 2013;15(4):e71 [FREE Full text] [doi: 10.2196/jmir.2222] [Medline: 23583917]

65. Masalski M, Grysiński T, Kręcicki T. Hearing tests based on biologically calibrated mobile devices: comparison with pure-tone audiometry. JMIR Mhealth Uhealth 2018 Jan 10;6(1):e10 [FREE Full text] [doi: 10.2196/mhealth.7800] [Medline: 29321124]

66. Magro I, Clavier O, Mojica K, Rieke C, Eisen E, Fried D, et al. Reliability of tablet-based hearing testing in nicaraguan schoolchildren: a detailed analysis. Otol Neurotol 2020 Mar;41(3):299-307. [doi: 10.1097/MA0.0000000000002534] [Medline: 31851067]

67. Meinke DK, Norris JA, Flynn BP, Clavier OH. Going wireless and booth-less for hearing testing in industry. Int J Audiol 2017 Dec 15;56(sup1):41-51 [FREE Full text] [doi: 10.1080/14992027.2016.1261189] [Medline: 27976975]

68. Song X, Wallace B, Gardner J, Ledbetter N, Weinberger K, Barbour D. Fast, continuous audiogram estimation using machine learning. Ear Hear 2015;36(6):326-335 [FREE Full text] [doi: 10.1097/AUD.0000000000000186] [Medline: $\underline{26258575]}$

69. Heisey KL, Buchbinder JM, Barbour DL. Concurrent bilateral audiometric inference. Acta Acust United Acust 2018 Sep 01;104(5):762-765. [doi: 10.3813/aaa.919218]

70. Sun C, Liu Y, Wang X. An automated hearing test equipment based on active noise control technology. In: Proceedings of the IEEE International Instrumentation and Measurement Technology Conference (I2MTC). 2019 Presented at: IEEE International Instrumentation and Measurement Technology Conference (I2MTC); May 20-23, 2019; Auckland, New Zealand p. 1-5. [doi: 10.1109/i2mtc.2019.8827137]

71. Brennan-Jones CG, Eikelboom RH, Swanepoel DW, Friedland PL, Atlas MD. Clinical validation of automated audiometry with continuous noise-monitoring in a clinically heterogeneous population outside a sound-treated environment. Int J Audiol 2016 Sep 20;55(9):507-513. [doi: 10.1080/14992027.2016.1178858] [Medline: 27206551]

72. Swanepoel DW, Biagio L. Validity of diagnostic computer-based air and forehead bone conduction audiometry. J Occup Environ Hyg 2011 Apr 22;8(4):210-214. [doi: 10.1080/15459624.2011.559417] [Medline: 21391065]

73. Govender S, Mars M. Validity of automated threshold audiometry in school aged children. Int J Pediatr Otorhinolaryngol 2018 Feb;105:97-102. [doi: 10.1016/j.ijporl.2017.12.008] [Medline: 29447828]

74. Storey KK, Muñoz K, Nelson L, Larsen J, White K. Ambient noise impact on accuracy of automated hearing assessment. Int J Audiol 2014 Oct 09;53(10):730-736. [doi: 10.3109/14992027.2014.920110] [Medline: 24909592]

75. Swanepoel DW, Matthysen C, Eikelboom R, Clark J, Hall JW. Pure-tone audiometry outside a sound booth using earphone attentuation, integrated noise monitoring, and automation. Int J Audiol 2015;54(11):777-785. [doi: 10.3109/14992027.2015.1072647] [Medline: 26514954]

76. Bornman M, Swanepoel D, De Jager LB, Eikelboom R. Extended high-frequency smartphone audiometry: validity and reliability. J Am Acad Audiol 2019 Mar;30(3):217-226. [doi: 10.3766/jaaa.17111] [Medline: $\underline{\text { 30461416] }}$ 
77. Swanepoel DW, Myburgh HC, Howe DM, Mahomed F, Eikelboom RH. Smartphone hearing screening with integrated quality control and data management. Int J Audiol 2014 Dec;53(12):841-849. [doi: 10.3109/14992027.2014.920965] [Medline: 24998412]

78. Brittz M, Heinze B, Mahomed-Asmail F, Swanepoel DW, Stoltz A. Monitoring hearing in an infectious disease clinic with mhealth technologies. J Am Acad Audiol 2019 Jun;30(6):482-492. [doi: 10.3766/jaaa.17120] [Medline: 30461403]

79. Corona AP, Ferrite S, Bright T, Polack S. Validity of hearing screening using hearTest smartphone-based audiometry: performance evaluation of different response modes. Int J Audiol 2020 Sep;59(9):666-673. [doi: 10.1080/14992027.2020.1731767] [Medline: 32134341]

80. Rodrigues LC, Ferrite S, Corona AP. Validity of heartest smartphone-based audiometry for hearing screening in workers exposed to noise. J Am Acad Audiol 2021 Feb;32(2):116-121. [doi: 10.1055/s-0040-1718931] [Medline: 33296933]

81. Handzel O, Ben-Ari O, Damian D, Priel MM, Cohen J, Himmelfarb M. Smartphone-based hearing test as an aid in the initial evaluation of unilateral sudden sensorineural hearing loss. Audiol Neurootol 2013;18(4):201-207. [doi: 10.1159/000349913] [Medline: 23689282]

82. Khoza-Shangase K, Kassner L. Automated screening audiometry in the digital age: exploring uhear ${ }^{\mathrm{TM}}$ and its use in a resource-stricken developing country. Int J Technol Assess Health Care 2013 Jan;29(1):42-47. [doi: 10.1017/S0266462312000761] [Medline: 23298579]

83. Van Tasell DJ, Folkeard P. Reliability and accuracy of a method of adjustment for self-measurement of auditory thresholds. Otol Neurotol 2013 Jan;34(1):9-15. [doi: 10.1097/MAO.0b013e318278c05d] [Medline: 23202154]

84. Whitton JP, Hancock KE, Shannon JM, Polley DB. Validation of a self-administered audiometry application: an equivalence study. Laryngoscope 2016 Oct 02;126(10):2382-2388. [doi: 10.1002/lary.25988] [Medline: 27140227]

85. Yeung J, Javidnia H, Heley S, Beauregard Y, Champagne S, Bromwich M. The new age of play audiometry: prospective validation testing of an iPad-based play audiometer. J Otolaryngol Head Neck Surg 2013 Mar 11;42(1):21 [FREE Full text] [doi: 10.1186/1916-0216-42-21] [Medline: 23663317]

86. Thompson GP, Sladen DP, Borst BJ, Still OL. Accuracy of a tablet audiometer for measuring behavioral hearing thresholds in a clinical population. Otolaryngol Head Neck Surg 2015 Nov;153(5):838-842. [doi: 10.1177/0194599815593737] [Medline: 26183518]

87. Bastianelli M, Mark AE, McAfee A, Schramm D, Lefrançois R, Bromwich M. Adult validation of a self-administered tablet audiometer. J Otolaryngol Head Neck Surg 2019 Nov 07;48(1):59 [FREE Full text] [doi: 10.1186/s40463-019-0385-0] [Medline: 31699157$]$

88. Vijayasingam A, Frost E, Wilkins J, Gillen L, Premachandra P, Mclaren K, et al. Tablet and web-based audiometry to screen for hearing loss in adults with cystic fibrosis. Thorax 2020 Aug;75(8):632-639. [doi: 10.1136/thoraxjnl-2019-214177] [Medline: $\underline{\text { 32409613] }}$

89. Yalamanchali S, Albert RR, Staecker H, Nallani R, Naina P, J Sykes K. Evaluation of portable tablet-based audiometry in a South Indian population. Indian J Otolaryngol Head Neck Surg 2020 Sep 02. [doi: 10.1007/s12070-020-02094-3]

90. De Sousa KC, Swanepoel DW, Moore DR, Myburgh HC, Smits C. Improving sensitivity of the digits-in-noise test using antiphasic stimuli. Ear Hear 2020;41(2):442-450 [FREE Full text] [doi: 10.1097/AUD.0000000000000775] [Medline: 31425362]

91. Gescheider G. Psychophysics: The Fundamentals. East Sussex, United Kingdom: Psychology Press; 2013.

92. Brennan-Jones C, Eikelboom R, Bennett R, Tao K, Swanepoel D. Asynchronous interpretation of manual and automated audiometry: agreement and reliability. J Telemed Telecare 2016 Sep 20;24(1):37-43. [doi: 10.1177/1357633x16669899]

93. Margolis R, Saly G. Asymmetric hearing loss: definition, validation, and prevalence. Otol Neurotol 2008 Jun;29(4):422-431. [doi: $\underline{10.1097 / M A O .0 b 013 e 31816 \mathrm{c} 7 \mathrm{c09}]}$ [Medline: 18418281]

94. Crowson M, Lee J, Hamour A, Mahmood R, Babier A, Lin V, et al. AutoAudio: deep learning for automatic audiogram interpretation. J Med Syst 2020:163. [doi: 10.1101/2020.04.30.20086637]

95. Charih F, Bromwich M, Mark AE, Lefrançois R, Green JR. Data-driven audiogram classification for mobile audiometry. Sci Rep 2020 Mar 03;10(1):3962 [FREE Full text] [doi: 10.1038/s41598-020-60898-3] [Medline: 32127604$]$

96. Barbour DL, DiLorenzo JC, Sukesan KA, Song XD, Chen JY, Degen EA, et al. Conjoint psychometric field estimation for bilateral audiometry. Behav Res Methods 2019 Jun;51(3):1271-1285 [FREE Full text] [doi: 10.3758/s13428-018-1062-3] [Medline: 29949072]

97. Héder M. From NASA to EU: the evolution of the TRL scale in public sector innovation. Innov J 2017;22(2):1-23 [FREE Full text]

98. Technology Readiness Assessment (TRA) Deskbook. Department of Defense. 2009. URL: https://www.skatelescope.org/ public/2011-11-18 WBS-SOW Development Reference Documents/DoD TRA July 2009 Read Version.pdf [accessed 2022-01-14]

99. Garland A, Jenveja A, Patterson J. Psyberguide: a useful resource for mental health apps in primary care and beyond. Fam Syst Health 2021 Mar;39(1):155-157. [doi: 10.1037/fsh0000587] [Medline: 34014736] 


\section{Abbreviations}

PRISMA: Preferred Reporting Items for Systematic Reviews and Meta-Analyses

RMSD: root mean square deviation

TRL: technology readiness level

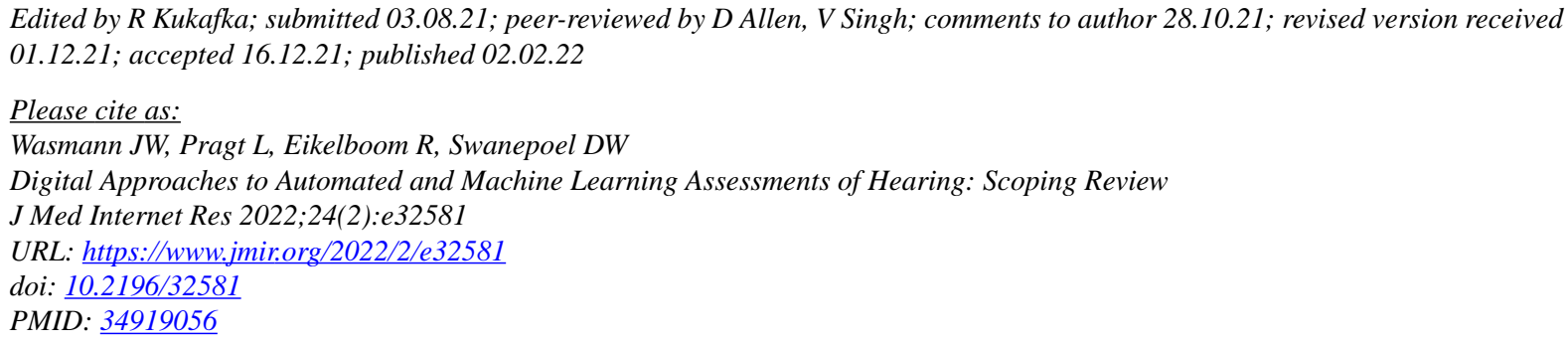

CJan-Willem Wasmann, Leontien Pragt, Robert Eikelboom, De Wet Swanepoel. Originally published in the Journal of Medical Internet Research (https://www.jmir.org), 02.02.2022. This is an open-access article distributed under the terms of the Creative Commons Attribution License (https://creativecommons.org/licenses/by/4.0/), which permits unrestricted use, distribution, and reproduction in any medium, provided the original work, first published in the Journal of Medical Internet Research, is properly cited. The complete bibliographic information, a link to the original publication on https://www.jmir.org/, as well as this copyright and license information must be included. 